\title{
ADSORPSI SENYAWA POLISIKLIK AROMATIK HIDROKARBON (PAH) OLEH KARBON AKTIF
}

\author{
Oleh \\ Deny Yogaswara ${ }^{1)}$
}

\begin{abstract}
PAH ADSORPTION BY ACTIVATED CARBON. The growing population and the rapid economic development have led an increasing input of waste waters mainly from industries, agriculture and households into marine environment. In addition, discharge of maritime transportation and accidents of oil spills contribute to the marine as pollutants. The released compounds have dangerious effects, for example hazard to human health, hindrance to marine activities, and impairment of the quality of seawaters. Because of hydrophobic character, these compound contaminants tend to be adsorbed to sediment particles and therefore it could be considered as pollution reservoirs. They are also accumulated in the aquatic organisms and biomagnified in the food chains. Some contaminants pose a health risk to aquatic organisms and ultimately to humans who consume contaminated seafood. Therefore, study of activated carbon adsorption will reduce organic pollution such as PAH in marine environment.
\end{abstract}

\section{PENDAHULUAN}

Kawasan pesisir merupakan lingkungan yang banyak terjadi kelimpahan bahan pencemar organik persisten. Situasi ini diperparah dengan munculnya kawasan industri padat penduduk sebagai komponen penting dalam kegiatan ekonomi, dan pada saat yang sama menyebabkan tercemarnya lingkungan baik langsung maupun tidak langsung. Polusi senyawa kimia di perairan laut merupakan ancaman terhadap lingkungan air dengan efek, seperti toksisitas akut dan kronis untuk organisme air, akumulasi polutan dalam ekosistem dan kerugian terhadap habitat dan keanekaragaman hayati, serta ancaman terhadap kesehatan manusia (Sánchez-Avila et al., 2012). Adanya senyawa polutan ke lingkungan dan dampaknya menjadi isu utama yang meningkatkan perhatian pada skala lokal, nasional, regional dan global. Ekosistem pesisir dan pelabuhan merupakan lokasi yang paling sensitif dan rentan terhadap dampak dari kegiatan manusia, menghadapi masalah utama lingkungan yang disebabkan oleh buangan dari lingkungan dan darat, polusi dari transportasi sungai, dan air limbah dari industri dan kegiatan perkotaan, yang mengancam kehidupan dan ekosistem laut pesisir (Halpern et al., 2008).

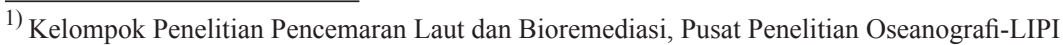




\section{KARAKTERISTIK KARBON AKTIF}

Karbon aktif adalah senyawa karbon, yang dapat dihasilkan dari bahan-bahan yang mengandung karbon yang diperlakukan secara khusus untuk mendapatkan permukaan yang lebih luas. Luas permukaan karbon aktif berkisar antara 300-3500 $\mathrm{m}^{2} /$ gram dan ini berhubungan dengan struktur pori internal yang menyebabkan karbon aktif mempunyai sifat sebagai adsorben. Karbon aktif dapat mengadsorpsi gas dan senyawa-senyawa kimia tertentu atau bersifat selektif, tergantung pada besar atau volume pori dan luas permukaan.

Karbon aktif berwarna hitam, tidak berbau, tidak berasa, dan mempunyai daya serap yang lebih besar dibandingkan dengan karbon yang belum menjalani proses aktivasi, serta mempunyai permukaan yang luas. Permukaan yang luas ini disebabkan karbon mempunyai permukaan dalam (internal surface) yang berongga (Gambar 1), sehingga mempunyai ke- mampuan menyerap gas, dan uap atau zat yang berada di dalam suatu larutan. Sifat dari karbon aktif yang dihasilkan tergantung dari bahan yang digunakan, misalnya, tempurung kelapa menghasilkan arang yang lunak dan cocok untuk menjernihkan air (Yang, 2003).

Karbon aktif menurut bentuknya dapat dibagi menjadi dua kelompok, yaitu bubuk dan granular. Karbon bentuk bubuk digunakan untuk adsorpsi dalam larutan. Misalnya untuk menghilangkan warna (decolorisation), sedangkan karbon bentuk granular digunakan untuk adsorpsi gas dan uap, dikenal pula sebagai karbon pengadsorpsi gas. Karbon bentuk granular kadang-kadang juga digunakan di dalam media larutan khususnya untuk deklrorinasi air dan untuk penghilang warna dalam larutan, serta pemisahan komponen-komponen dalam suatu sistem yang mengalir (Vargas et al., 2012).

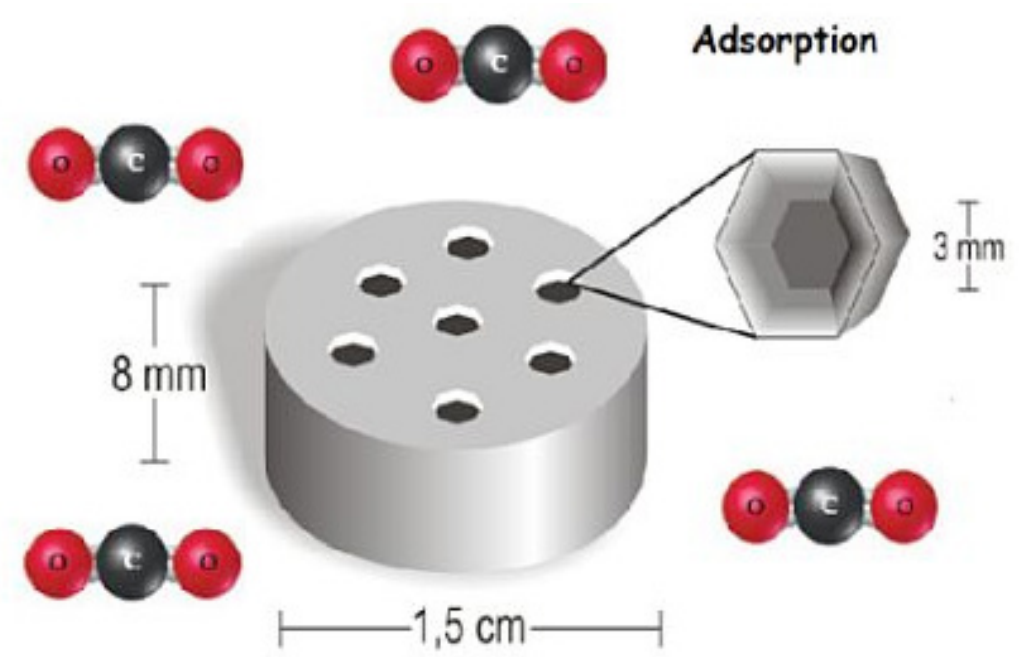

Gambar 1. Bentuk geometri porositas karbon aktif(Vargas et al., 2012) 
Adsorpsi merupakan peristiwa penyerapan suatu substansi pada permukaan zat padat. Pada fenomena adsorpsi, terjadi gaya tarik-menarik antara substansi terserap dan penyerapnya. Hal ini disebabkan oleh gaya Van der Waals, yakni adanya gaya tarik-menarik antara molekul fluida dengan molekul pada permukaan padatan (intermolekular) yang energinya lebih kecil dari pada gaya tarik menarik antar molekul fluida itu sendiri (intramolekular). Dalam sistem adsorpsi, fasa teradsorpsi dalam solid disebut adsorbat sedangkan pengadsoprsinya disebut adsorben. Pada proses adsorpsi, molekul adsorbat bergerak melalui bulk fasa gas menuju permukaan padatan dan berdifusi pada permukaan pori padatan adsorben.

Proses adsorpsi hanya terjadi pada permukaan, tidak masuk dalam fasa bulk/ruah. Proses adsorpsi terutama terjadi pada mikropori (pori-pori kecil), sedangkan tempat transfer adsorbat dari permukaan luar ke permukaan mikropori ialah makropori (Yang, 2003).

Berbagai teknologi pengolahan telah dilakukan untuk menghilangkan polutan organik. Prinsip dari teknikteknik tersebut antara lain adalah adsorpsi, reaksi kimia, filtrasi, pertukaran ion, koagulasi/flokulasi, osmosis balik, elektrodialisis, dan lain-lain. Adsorpsi pada permukaan karbon aktif adalah metode yang paling banyak digunakan untuk menghilangkan fenol dari air limbah. Umumnya, karbon aktif memainkan peran penting dalam perawatan air dan berfungsi sebagai media penghilang kontaminan.
Selain itu, karbon aktif juga telah digunakan sebagai adsorben selama puluhan tahun untuk menghilangkan kontaminan dari limbah industri. Karbon aktif umumnya diterapkan dalam menghilangkan polutan beracun, seperti fenol dan turunannya yang berperan penting pada senyawa organik yang ada dalam limbah industri (Hameed et al., 2009). Penggunaan karbon aktif yang sangat luas ini dapat juga digunakan sebagai adsorben untuk mengadsorpsi senayawa organik. Hal ini karena karbon aktif memiliki porositas yang besar, daya adsorpsi yang tinggi dan harganya yang ekonomis. Sedangkan kekurangannya yaitu sulit untuk diregenerasi (Radet al., 2014). Karbon aktif juga terkenal, karena efektifitasnya dalam menghilangkan bahan senyawa kimia organik dari limbah (Krishnaiah et al., 2013).

Karbon aktif dapat diproduksi dari setiap jenis bahan yang mengandung karbon. Bahan baku yang paling umum digunakan untuk penggunaan komersial adalah batubara, gambut, lignit, kayu, tempurung kelapa, dan produk samping pertanian (sekam padi dan jerami). Karbon aktif memiliki karakteristik yaitu memiliki luas permukaan yang tinggi, struktur mikro, volume pori, kapasitas adsorpsi yang besar, regenerasi yang efektif, dan sifat kimia di permukaannya (Tham et al., 2011). Porositas karbon aktif yang tinggi, menyebabkan bahan ini banyak digunakan dalam industri pemurnian dan operasi pendaurulangan senyawa kimia. Modifikasi dan teknik impregnasi telah diterapkan untuk meningkatkan adsorpsi permukaan, kapasitas porositas 
dan menambahkan selektivitas terhadap karbon. Ada dua proses dalam memodifikasi karbon aktif, dengan aktivasi fisika dan aktivasi kimia. Metode fisika melibatkan dua proses tahap pirolisis prekursor, yang berada di atmosfer inert yakni tidak terjadinya reaksi tertentu saat proses ini berlangsung, dan aktivasi produk padat residu pada suhu tinggi. Perlakuan untuk aktivasi kimia dapat dilakukan dengan menambahkan senyawa kimia asam sesuai dengan tingkat keasaman yang dibutuhkan (Yavuz et al., 2010).

\section{ADSORPSI KARBON AKTIF TERHADAP NAPHTHALENE DAN PHENATHRENE}

Lingkungan pesisir banyak terdapat zat pencemar dari senyawa organik, salah satunya adalah Poli Aromatik Hidrokarbon (PAH). PAH memiliki sifat persisten, karsinogenik, dan bersifat toksik terhadap lingkungan dalam jangka panjang. PAH terbentuk ketika adanya gabungan dua atau lebih cincin aromatik menjadi satu senyawa. Sifat fisik dan kimianya tergantung pada berat molekulnya. Berat molekul PAH mulai dari yang kecil, 2-3 cincin aromatik (naphthalene, fluorene, phenanthrene, dan anthracene) masuk ke dalam golongan Low Molecular Weight (LMW), dan berat molekul besar, 4-7 cincin aromatik (chrysene) masuk ke dalam golongan High Molecular Weight (HMW). PAH dengan berat molekul besar bersifat sangat toksik dibandingkan dengan yang memiliki berat molekul kecil meskipun secara umum semuanya dapat bersifat toksik dan karsinogenik.
Kelarutan dalam air rendah, sehingga cenderung menyerap dan terakumulasi dalam sedimen dan degradasi PAH dengan berat molekul tinggi sangat lambat (Perelo, 2010). Pengurangan jumlah PAH di lingkungan laut perlu dilakukan karena sifat PAH yang karsinogenik dan sulit didegradasi. Jumlah PAH yang berakumulasi secara periodik berpotensi berdampak buruk bagi lingkungan dalam jangka panjang (Haritash \& Kaushik, 2009). PAH tidak efektif dihilangkan dengan metode fisika-kimia seperti koagulasi, flokulasi, sedimentasi, filtrasi atau ozonisasi. Namun, proses adsorpsi mampu secara efektif menghilangkan polutan persisten dari senyawa organik seperti PAH. Proses adsorpsi tersebut dapat menggunakan karbon aktif (Radet al., 2014).

\section{KARAKTERISKTIK SENYAWA NAPHTHALENE DAN PHENANTHRENE}

\section{Senyawa Naphthalene}

Ada 16 senyawa PAH prioritas yang direkomendasikan oleh U.S EPA (Environmental Protection Agency), salah satunya adalah naphthalene (USEPA, 1984). Naphthalene merupakan senyawa alami pada batu bara dan biasanya digunakan sebagai pengawet kayu, penolak serangga, dan bahan baku untuk memproduksi metilantranilat, ester ftalat, kloronaphthalene, resin sintetis, dan lain lain. Naphthalene bersumber dari udara, terutama dari pembakaran batu bara dan minyak bumi. Jika dibandingkan dengan 
jenis PAH lainnya, naphthalene adalah jenis PAH yang paling sederhana (Gambar 2), mempunyai toksisitas yang rendah dan mudah ditemukan di lingkungan (Budhwani, 2015).

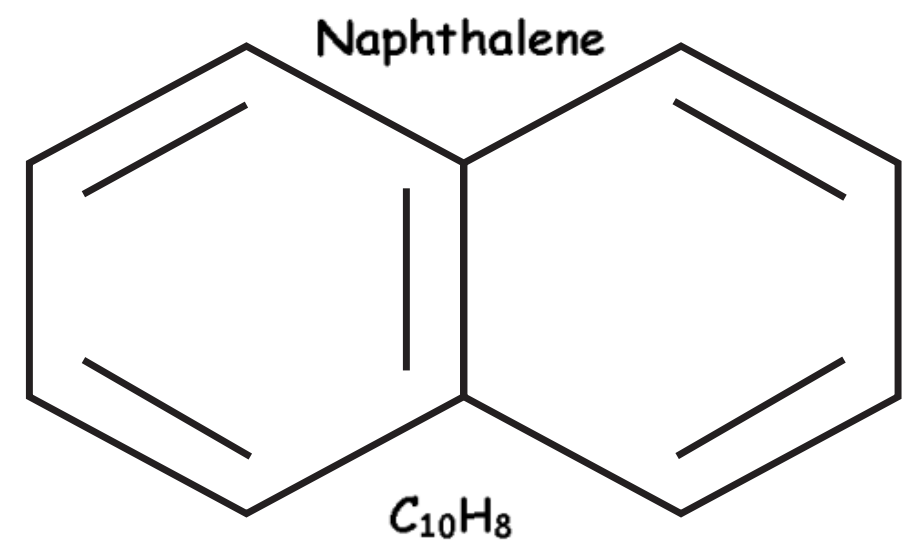

Gambar 2. Struktur kimia naphthalene (USEPA, 1984).

\section{Senyawa Phenanthrene}

Phenanthrene juga termasuk ke dalam 16 senyawa PAH prioritas yang direkomendasikan oleh U.S EPA (Environmental Protection Agency). Phenan- threne memiliki konsentrasi tinggi di minyak bumi, memiliki tiga cincin benzene yang saling terikat (Gambar 3), mudah larut dalam pelarut organik, dan bersifat hidrofobik (USEPA, 1984).

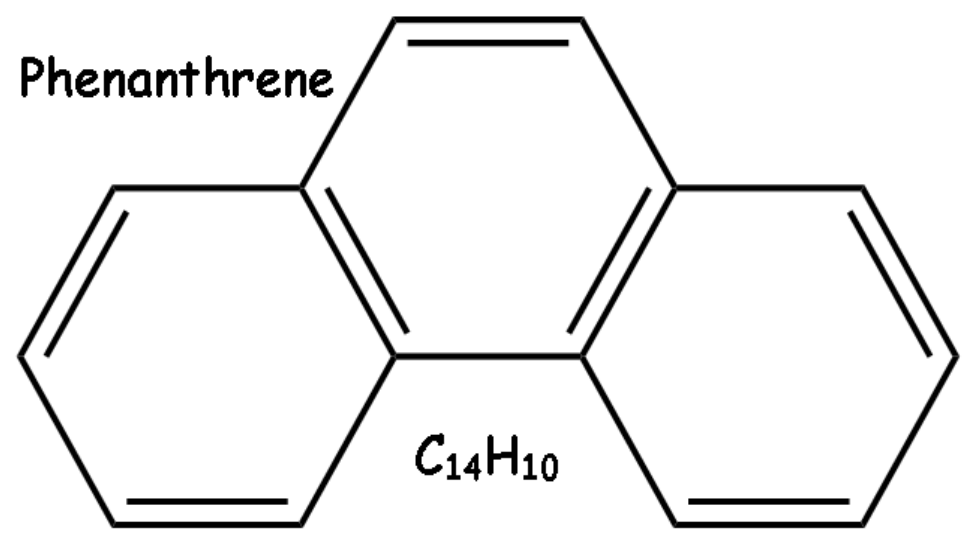

Gambar 3. Struktur kimia phenanthrene (USEPA, 1984). 


\section{Adsorpsi karbon aktif terhadap naphthalene}

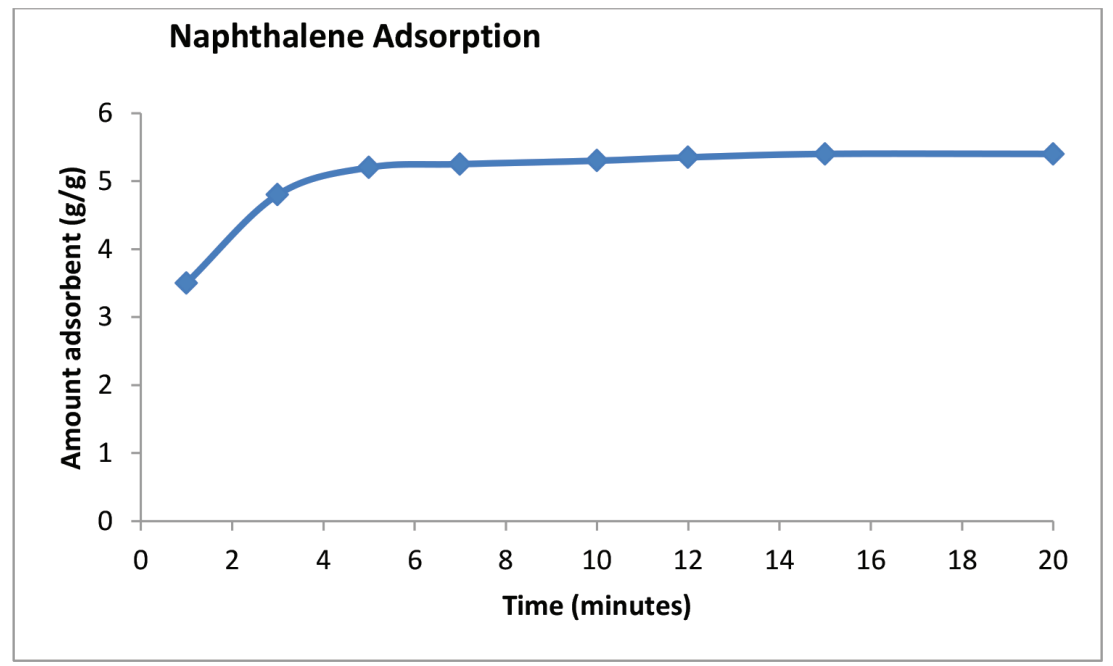

Gambar 4. Adsorpsi karbon aktif (adsorben) terhadap naphthalene (Budhwani, 2015).

Karbon aktif mampu mengadsorpsi secara efektif terhadap naphthalene seperti terlihat pada gambar 4. Kemampuan adsorben (karbon aktif) mengadsorpsi naphthalene semakin meningkat dan optimal seiring dengan meningkatnya waktu kontak hingga menemui titik jenuh adsorpsi. Ini menunjukkan bahwa karbon aktif dapat digunakan sebagai adsorben untuk mengadsorpsi naphthalene secara efektif (Budhwani, 2015).

\section{Adsorpsi kabron aktif terhadap phenanthrene}

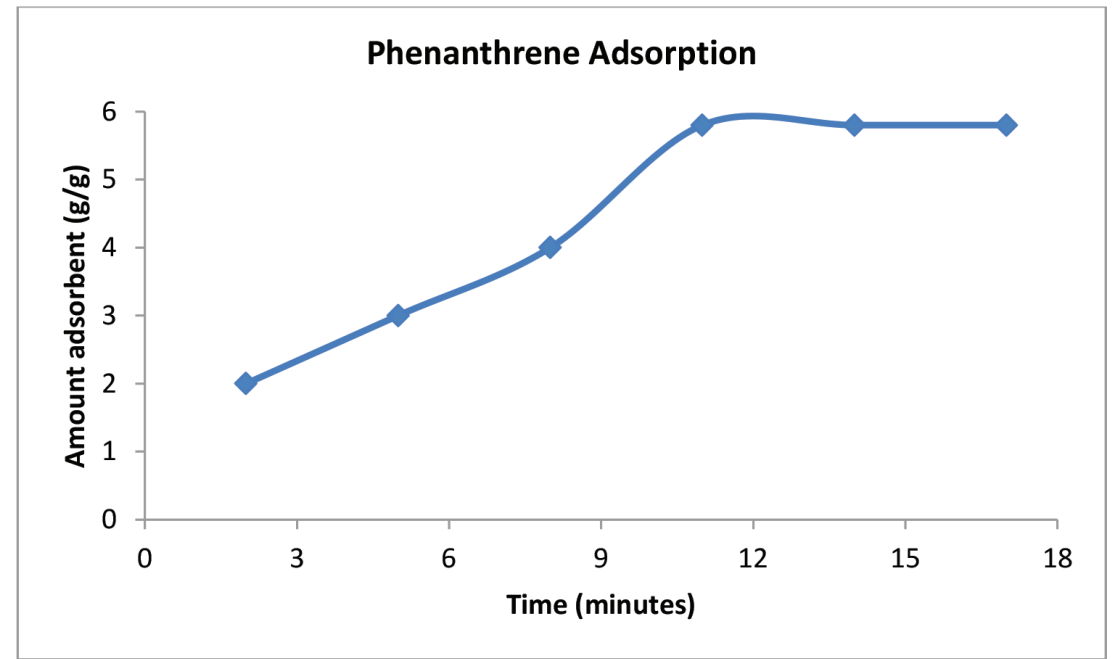

Gambar 5. Adsorpsi karbon aktif (adsorben) terhadap phenanthrene (Rad et al., 2014). 
Pada Gambar 5 dapat dilihat bahwa karbon aktif secara efektif mampu mengadsorpsi senyawa phenanthrene. Semakin meningkat waktu kontak adsorben terhadap senyawa phenanthrene maka semakin meningkat pula jumlah adsorpsi karbon aktif hingga mencapai titik jenuh (Rad et al., 2014).

\section{PENUTUP}

Proses adsorpsi karbon aktif terhadap senyawa PAH (naphthalene dan phenanthrene) dapat berlangsung secara efektif. Hal ini ditandai dengan semakin meningkatnya waktu kontak karbon aktif (adsorben) terhadap senyawa PAH (naphthalene dan phenanthrene) maka semakin meningkat pula nilai adsorpsinya. Untuk lebih meningkatkan kemampuan adsorpsinya perlu dilakukan modifikasi terhadap adsorben karbon aktif, baik itu dilakukan secara fisika maupun kimia. Proses adsorpsi ini dapat juga digunakan untuk mengadsorpsi senyawa PAH jenis lain, dan juga senyawa organik lainnya yang sesuai dengan karakterisktik adsorben karbon aktif.

\section{DAFTAR PUSTAKA}

Budhwani, N. 2015. Removal of Polycyclic Aromatic Hydrocarbons Present in Tyre Pyrolytic Oil Using Low Cost Natural Adsorbents. Environmental and Ecological Engineering. Vol. 9, No. 2: 186-190.

Halpern, B.S., S. Walbridge, K.A. Selkoe, C.V. Kappel, F. Micheli,
C.D’Agrosa, J.F. Bruno, K. S. casey, C. Ebert, H.E. Fox, R. Fujita, D. Heinemann, H. S. Lenihan, E.M.P. Madin, M.T. Perry, E.R. Selig, M. Spalding, R. Steneck, and R. Watson. 2008. A Global Map of Human Impact on. Science, 319 (2008), pp. 948-953.

Hameed, B.H., I.A.W. Tan, and A. L. Ahmad. 2009. Preparation of oil palm empty fruit bunch-based activated carbon for removal of 2,4,6-trichlorophenol: Optimization using response surface methodology. Journal of Hazardous Materials, 164(2-3), pp.1316-1324.

Haritash, A.K. and C.P. Kaushik. 2009. Biodegradation aspects of polycyclic aromatic hydrocarbons (PAHs) : a review. Journal of Hazardous of materials (169) : 1-15.

Krishnaiah, D.,S.M. Anisuzzaman, A. Bono, andR. Sarbatly. 2013. Adsorption of 2,4,6-trichlorophenol (TCP) onto activated carbon. Journal of King Saud University - Science, 25(3), pp.251-255.

Perelo, L.W. 2010. Review: In situ and bioremediation of organic pollutants in aquatic sediments. Journal of Hazardous Materials (177): 81-89.

Rad, R. M., L. Omidi, H. Kakooei, F. Golbabaei, H. Hassani, R.A. Loo, and K. Azam. 2014. Adsorption of Polycyclic Aromatic Hydro- 
carbons on Activated Carbons: Kinetic and Isotherm Curve Modeling. International Journal of Occupational Hygiene. IJOH: 43-49.

Sánchez-Avila, J., R Tauler, and S. Lacorte. 2012. Organic Micropollutants In Coastal Waters From NW Mediterranean Sea: Sources Distribution And Potential Risk. Environment International, 46, pp.50-62.

Tham, Y.J.,P. A. Latif, A. M. Abdullah, A. S. Devi, and Y. H. T. Yap. 2011. Performances of toluene removal by activated carbon derived from durian shell. Bioresource Technology, 102 (2), pp.724-728.

USEPA. 1984. Health effects assessment for polycyclic aromatic hydrocarbons (PAHS). In Health and Environment Assessment. U.S Environmental Protection Agency. Chicago, Illinois: 49 hlm.
Vargas, D.P., L. Giraldo, and J.C. Moreno-Piraján. 2012. $\mathrm{CO}_{2}$ adsorption on activated carbonhoneycomb-monoliths:a comparison of langmuir and tóth models. Int. $J$. Mol. Sci. , 13, 8388-8397.

Yavuz, R.,H. Akyildiz, N. Karatepe, and E. Cetinkaya. 2010. Influence of preparation conditions on porous structures of olive stone activated by $\mathrm{H}_{3} \mathrm{PO}_{4}$. Fuel Processing Technology, 91 (1), pp.80-87.

Yang, R.T. 2003. Adsorbent: Fundamentals and Applications. John Wiley and Sons, Inc. Hoboken, New Jersey: $381 \mathrm{hlm}$. 